\title{
En elogio de la burocracia. Paul Du Gay. Madrid: Siglo XXI, 2012
}

\author{
Daniel Lara De La Fuente \\ Universidad Complutense de Madrid \\ dalara01@ucm.es
}

Cuando en la mente de cualquier persona, ya se dedique a la sociología 0 a cualquier actividad mundana más, aparece el término burocracia, parece seguro apostar su asociación inmediata a la administración pública. También es presumible que sus funcionarios, apegados a los procedimientos, obedientes al mando de una cadena jerárquica y paladines de la impersonalidad, no sean considerados usualmente agentes que destaquen por sus virtudes éticas. Contrariamente a esta idea establecida, la obra de Paul du Gay tiene como propósito central poner de relieve que estas normas de comportamiento, entre otras arquetípicas de la función pública burocrática, componen una esfera ética sustantiva injustamente valorada.

El núcleo de la defensa del funcionario público se basa en una interpretación, ajena al canon, del clásico insoslayable sobre el asunto, Max Weber. Esto pone de relieve, como señala la inagotable cita de Italo Calvino rescatada por Luis Enrique Alonso en el prólogo, que los clásicos nunca terminan de decir todo lo que quieren decir. Ajena a la teoría de la racionalización y a la metáfora de la jaula de hierro, esta interpretación concibe la burocracia como un orden de vida dotado de unas normas y valores que componen una personalidad específica -el burócrata - y como resultado, frágil y contingente, de logros morales. Sin dichos logros, no podrían seguir manteniéndose elementos considerados de progreso, como la protección de la arbitrariedad de la autoridad política 0 el gobierno representativo.

Por ello, es irremediable que esta concepción sea incompatible con las principales críticas realizadas a la burocracia, cuyas inconsistencias son señaladas en los tres primeros capítulos del libro. Tales críticas están dotadas de un nexo común: la ceguera a la existencia, dentro de los entramados sociales modernos, de esferas éticas sustantivas, autónomas e irreductibles dotadas de normas, valores y dinámicas propias, entre las cuales figura la burocracia pública. Ello implica que tratar de subsumirlas bajo un único patrón — sea éste la empresa 0 un ideal de vida buena - conlleva necesariamente un fracaso en tanto que desvirtúa el cumplimiento de las tareas a las que deben su razón de ser. Dicho de otra manera, las críticas en última instancia no tienen una adecuada comprensión de la burocracia pública en tanto que es interpretada como un fragmento de una totalidad perdida que ha de ser recompuesta.

La primera crítica tratada es la realizada por el filósofo comunitarista Alasdair MacIntyre. Tal crítica está enfocada en el gerente público, el cual sería la personificación de una moral emotivista que propugna la satisfacción de preferencias individuales usando para ello la adecuación entre medios y fines con independencia de criterios morales. Ello sería el síntoma paradigmático de la pérdida moderna del ideal de vida buena que antaño cohesionaba las comunidades, siendo sustituida por el intento utópico, abanderado por la burocracia y la ciencia, de controlar los aspectos de la vida social empleando la razón instrumental. La inconsistencia de la propuesta de Maclntyre de un telos que restaure la comunidad es palpable según Du Gay por el hecho de que éste provendría y sería ajeno al mismo tiempo de las prácticas sociales en que se inscribe, sin ser resuelto 0 encauzado este argumento dialéctico. Al mismo tiempo, su crítica es equivocada en tanto en cuanto se interpreta el gerente como un fragmento de la personalidad moral completa, cuya contraparte sería la del intelectual crítico, lo cual es erróneo si se tiene en cuenta que la personalidad del burócrata engloba una serie de reglas de comportamiento que las hacen formar una esfera moral propia, sin las cuales no existiría. De ahí la 
quimera, en términos de Du Gay, de plantear una burocracia pública formada por personalidades morales completas tal como las concibe Maclntyre.

La senda de la interpretación de la burocracia como fracaso moral es seguida por la segunda crítica, formulada por el célebre Zygmunt Bauman. La tarea aquí es señalar que sus fundamentos históricos y sociológicos, conducentes a otorgar un papel esencial a la burocracia en la ejecución del holocausto judío por parte del III Reich, son errados. De manera parecida a MacIntyre, la burocracia para el polaco es una muestra más del avance de una racionalidad instrumental en todas las esferas sociales desvinculada de normas morales. Es su complejo sistema de división del trabajo, su cadena jerárquica de mando, su objetividad y su impersonalidad las que producen una separación creciente entre los actos realizados por los funcionarios y sus consecuencias. De ahí que fuera idónea para poder Ilevar a cabo tal tarea, dificultando a los burócratas ejecutores de las políticas de exterminio responsabilizarse moralmente de lo que comportaba la realización de las tareas asignadas.

Naturalmente, tal supuesto sociológico acerca de la burocracia, basado en la teoría de la racionalización weberiana, choca con el núcleo de la interpretación de du Gay, el cual señala una aplicación acrítica y descontextualizada del arsenal conceptual de Weber por parte de Bauman y su escaso rigor histórico si se aplica al III Reich. Si éste alega que fue necesario el entramado estatal heredado de la República de Weimar para ejecutar con eficiencia el exterminio, el autor por el contrario señala que hubo de desmantelarse a marchas forzadas, tratando de formar funcionarios entusiastas con la causa - lo cual excluye toda imparcialidad y objetividad del ethos burocrático y su subsunción en el propio del político carismático-y entorpecer la dinámica burocrática convencional en favor de sus objetivos políticos. La impronta racial de éstos además atenta directamente contra el criterio de impersonalidad, lo cual se ve con claridad en la fijación contra sectores determinados de población. En definitiva, el III Reich supone una mezcla entre esferas, siendo colonizada la administración por la del liderazgo político. Interesante sería hilar esta argumentación con la de un clásico habitualmente olvidado, el Behemoth del politólogo y jurista Franz Neumann, en su interpretación de este régimen político como imperio de la anomia comandado por la autoridad carismática del Führer.

La tercera crítica la constituyen los discursos empresariales contemporáneos procedentes de gurús como Tom Peters o Rosabeth Kanter, encuadrados en lo que se ha hecho llamar managerialism. Su inconsistencia en este caso es situada por du Gay en las consecuencias - en términos de pérdida de igualdad o imparcialidad en el servicio a la ciudadanía propiciadas por prácticas como atenerse a los procedimientos - que conllevaría la adopción, por parte de los funcionarios públicos, de normas de conducta propias del emprendizaje empresarial. Tal fagocitación de la esfera burocrática supone la punta de lanza de todo un discurso teológico secularizado, cuyos gurús harían las veces de profetas de una nueva religión. Estas autoridades carismáticas anuncian la llegada de una nueva situación, precipitada por la globalización, caracterizada por su carácter cambiante e incierto, cuya adaptación requiere nuevas demandas y cualidades como la flexibilidad y el espíritu emprendedor. Dichas cualidades son las que habría de adoptar la burocracia pública, anquilosada en las reglas abstractas y los procedimientos, si quiere adaptarse al nuevo contexto. Para ello, sus trabajadores han de realizarse plenamente, pues el desempeño de sus funciones no ha de ser tedioso y percibido como una obligación permanente. Tal plenitud se alcanzaría mediante el emprendizaje, recomponiéndose la integridad de una personalidad escindida a causa de los rígidos y caducos requerimientos de la burocracia tradicional. Según du Gay, ello implica de facto la adopción de valores absolutos que subsuman las distintas esferas de lo social, equiparándose el emprendizaje a la conversión religiosa.

En combinación con el managerialism, hay una cuarta crítica que ha logrado cristalizarse institucionalmente. Tal es el programa denominado "gobierno empresarial" o Nueva Gestión Pública, propugnado por Ted Gaebler y David Osborne, compuesto por diez principios aplicados de forma heterogénea en las Administraciones Públicas de algunos países de la OCDE. Aunque no ha podido instaurarse en países como Alemania y Japón, sí lo 
ha podido hacer en buena medida en Reino Unido, el caso paradigmático. Antes de explicar brevemente éste y sus repercusiones éticas y políticas, conviene aclarar sus nociones básicas.

El pilar fundamental de esta propuesta es la interpretación de los principios de la empresa comercial como modelo a exportar por cualquier entramado organizativo encaminado a la provisión de bienes y servicios. Ello implica la proliferación de la forma contractual y un cambio de las pautas de comportamiento del funcionariado, delegándose tareas específicas en unidades de gestión autónomas desempeñadas por empleados emprendedores que responden de su actuación y de sí mismos abandonando las normas básicas del ethos burocrático tradicional, consideradas un obstáculo para la consecución de los objetivos.

El estudio de caso para el análisis de las repercusiones de este modelo lo ofrece el sector público británico, a partir de la implementación del programa "Próximos Pasos" durante los últimos compases de la administración Thatcher. Sus implicaciones, tras la creación de Agencias Ejecutivas autónomas de los ministerios, se analizan sobre dos grandes bloques. Por un lado, la ficción sostenida por esta iniciativa de separar tajantemente política y administración y las tareas de los políticos y los funcionarios ha tenido como consecuencia el deterioro de la actividad parlamentaria de control al ministro, al poder éste eludir sus responsabilidades según su conveniencia y desviarla a los encargados de las Agencias Ejecutivas. Al mismo tiempo, pone en entredicho la valoración pública del funcionariado, al no disponer del "paraguas" que constituía el hecho de que fuera el ministro el que asumiera la totalidad de las responsabilidades de lo que ocurriera en su ministerio. Por otra parte, la idea de inculcar en el personal de la administración ideales como el entusiasmo en la gestión de las políticas en lugar de mostrar sus posibles inconvenientes, implica peligros para el mantenimiento de normas básicas como la imparcialidad y la responsabilidad propias del ethos burocrático. Ello podría desembocar según du Gay en efectos perniciosos como la corrupción y la pérdida de imparcialidad y fiabilidad en la actuación de las administraciones.

Estas reformas administrativas implantadas en Reino Unido son justificadas por el discurso de la globalización, cuyo sedicente objetivo es la eficiencia económica en tanto garante del mantenimiento del bienestar y la seguridad nacional. Su persecución implica, como indica du Gay, que el tejido social del que forma parte la administración pública ha de estar a expensas de una esfera económica que se presupone autorregulada y en cuya eficiencia se confía su supervivencia. Ello se inserta en un nuevo proyecto utópico, en tela de juicio desde la crisis, de establecer un mercado autorregulado a escala mundial, cuyo primer intento fue analizado con rigor por Karl Polanyi en su clásico $L a$ Gran Transformación.

De esta manera se entienden mejor las iniciativas gubernamentales propugnadas a favor de la introducción de mecanismos de mercado dentro de los departamentos ministeriales — con el ejemplo de las Agencias Ejecutivas - y su miopía al no ser conscientes de sus verdaderas consecuencias más allá del terreno financiero. La argumentación de du Gay contra estas justificaciones tiene una doble vertiente. Por un lado, este discurso asume que eficiencia, efectividad y menores costes son términos intercambiables, algo más que cuestionable si se tiene en cuenta que es más que probable que entren en conflicto en contextos concretos, priorizándose unos a costa de otros. Por otro, propugnar la "despolitización" de la administración, separando la actividad de gestores y políticos, acarrea consecuencias que van más allá de lo financiero. Otorgar a los primeros mayores cotas de discrecionalidad, con el consiguiente alivio de la carga de responsabilidad de los segundos, implica en última instancia poner en tela de juicio normas básicas del gobierno representativo — como la responsabilidad del ministro ante el parlamento antes mencionada- si éstas quedan subyugadas a criterios económicos. En términos globales, esta transformación comporta una desaparición gradual de las funciones sociales de la burocracia tal como las hemos conocido.

La profundización en el asunto de la distinción entre las personalidades del político y el burócrata ocupa el sexto capítulo del libro. Una de las formas de realizar dicha distinción, contra la que du Gay argumenta, es la separación tajante entre la actividad del político y el funcionario antes mencionada. Su pilar fue levantado por el mismísimo Woodrow 
Wilson con el objetivo de evitar posibles malas prácticas de la administración, cuya expresión plástica sería la del operador - el gobernante que crea políticas — y la máquina —la administración gestora que las implementa. Además de describir con poca fidelidad y tener serias dificultades para concretarse en las prácticas cotidianas de gobierno, esta propuesta, aparentemente despolitizadora, tiene dos grandes consecuencias. Por una parte, otorga mayor control al gobernante, el cual no espera de los funcionarios asesoramiento honesto con independencia de lo que aquél quiera oír, sino mayor compromiso con sus políticas, lo cual irónicamente incrementa la politización del funcionariado de alto rango. Esta politización de facto se produce por la adopción de las normas de comportamiento gerencial — tratado en el tercer capítulo del libro-, al asumir el burócrata cotas crecientes de responsabilidad y autonomía en su labor. Esto en Reino Unido ha llegado a su máximo apogeo con algunos altos funcionarios rindiendo cuentas en medios de comunicación a la forma del político, permitiendo que éste en calidad de ministro pudiera eludir su responsabilidad. La consecuencia más grave de esto según du Gay es el progresivo abandono del viejo ethos de la función pública al ser sustituido por las normas de comportamiento del ejecutivo de empresa, sin ser nuevamente consciente de los distintos órdenes de vida que rigen a las dos personalidades constituidas por el funcionario público y el empresario.

En consecuencia, este abandono pone en peligro una de las dos grandes patas del gobierno representativo tal y como se ha conocido hasta hoy. Dos patas - las personalidades del político y el servidor público - cuyos órdenes de vida, diferenciados y en tensa convivencia, son esenciales para su mantenimiento en conexión con el interés público. Como trata de hacer ver du Gay, este interés público, ajeno al partidismo, es el que va minándose en favor de la "reinvención entusiasta" de la administración en los últimos tiempos, con los consiguientes efectos ético-políticos de calado. La conclusión es contundente: los imperativos éticos que guían la conducta de la burocracia pública siguen siendo esenciales. 